\title{
Preparation of Euyrycoma Longifolia Jack (E.L) Tongkat Ali (Ta) Root Extract Hydrogel for Wound Application
}

\author{
Maryam Riyadh Yaseen ${ }^{1}$, Ghasak G Faisal ${ }^{2, *}$, Azliana Abd Fuaat ${ }^{3}$, Khairunisa Ahmad Affandi $^{3}$, Batoul Alallam ${ }^{4}$, \\ Mohd Hamzah Mohd Nasir ${ }^{5}$
}

\section{Maryam Riyadh Yaseen', Ghasak G Faisal ${ }^{2, *}$, Azliana Abd Fuaat ${ }^{3}$, Khairunisa Ahmad Affandi ${ }^{3}$, Batoul Alallam ${ }^{4}$, Mohd Hamzah Mohd Nasir ${ }^{5}$}

'Department of Pathology and Laboratory Medicine, Faculty of Medicine, International Islamic University, MALAYSIA.

${ }^{2}$ Associate Professor, Department of Fundamental Dental and Medical Sciences, Faculty of Dentistry, International Islamic University, MALAYSIA.

${ }^{3}$ Assistant Professor, Department of Pathology and Laboratory Medicine, Faculty of Medicine, International Islamic University, MALAYSIA.

${ }^{4}$ Department of Pharmaceutical Technology, Faculty of pharmacy, International Islamic University, MALAYSIA.

${ }^{5}$ Department of Biotechnology, Faculty of Science, International Islamic University, MALAYSIA.

\section{Correspondence}

Assoc.Prof.Dr. Ghasak Ghazi Faisal

Department of Fundamental Dental and Medical sciences, Kulliyyah of Dentistry, International Islamic University, MALAYSIA.

E-mail:drghassak@gmail.com

History

- Submission Date: 02-08-2021;

- Review completed: 24-08-2021;

- Accepted Date: 01-09-2021.

DOI : 10.5530/pj.2021.13.185

Article Available online

http://www.phcogj.com/v13/i6

\section{Copyright}

(C) 2021 Phcogj.Com. This is an openaccess article distributed under the terms of the Creative Commons Attribution 4.0 International license.

\section{ABSTRACT}

Background: It is undeniable that a lot of patients worldwide suffer from different types of wounds. The complex process of wound healing has a severe effect on the life quality of patients as well as causing an economic load on healthcare institutions. Although the availability of various therapies for managing patients with acute and chronic wounds for the past decade, these therapies are usually expensive and accompanied by undesirable side effects. Hence, the discovery of a new arsenal for wound healing remains a hot topic of research. Recently, plants and their by-products have garnered remarkable attention as a source of therapeutic agents to treat wounds. This is because medicinal plants provide a rich reservoir of phytochemicals that could potentially become affordable and effective therapeutic agents. Eurycoma longifolia Jack or Tongkat Ali (TA), is one of the well-known traditional plants of Malaysia, it has been scientifically proven to have medicinal properties. Hydrogels are hydrophilic polymer networks that can imbibe a significant number of fluids. In comparison to other systems developed for herbal medicines delivery, a unique power possessed by hydrogels is the high-water absorption ability. This ability has favoured the loading of herbal formulations, which are in general hydrophilic in nature, into hydrogels. Objective: The aim of this study is to prepare Eurycoma longifolia Jack (E.I.J) Tongkat Ali (TA) roots hydrogel for wound application. Methods: Authentication of Eurycoma longifolia Jack roots was done by microscopic examination using methylene blue and Lugol's iodine solution. Root extraction by Soxhlet technique. In vitro cytotoxicity of ethanol extract of the roots was evaluated in human primary gingival fibroblasts cells. The ethanolic extract was loaded into hydrogel as a suitable dosage form for further wound healing studies. Results: The crude herbal drug sample, TA present the same microscopical characters to that of E. longifolia Jack tap root. Ic50 was $118.5 \mu \mathrm{g} / \mathrm{mL}$. The hydrogel was prepared using $2 \%$ xanthan gum and ethanol extract of TA was loaded successfully for its later application as a wound healing agent.

Key words: Eurycoma longifolia Jack, Microscopic examination, Hydrogel.

\section{INTRODUCTION}

Wound healing is an elaborate and intricate biological action commenced in response to an attack on the functioning and anatomy of normal healthy skin ${ }^{1}$.

Wound healing is a dynamic and complicated process involves an organized and an outstanding orchestrated process consisting of overlapping events such as haemostasis, inflammation, proliferation and extracellular matrix (ECM) remodelling ${ }^{2}$.

All these events are controlled by an intricate signalling mechanism that includes various cytokines, chemokines and growth factors ${ }^{3}$.

The repair process involves the interplay of growth factors, cytokines and cells involved in closing the injury ${ }^{4}$.

When wound healing does not proceed normally as a result of impairment in any of stages of the cascade this leads to either pathological scarring like keloid scar or chronic wound like venous ulcer ${ }^{5}$.

Medicinal plants have reached noticeable acceptability as therapeutic medication for wide variety of diseases as a result of adverse effects of contemporary medicines. WHO has predicted that about $80 \%$ of the population around the world believes in the importance and efficiency of medicinal plants. More than $85 \%$ of herbal medicines are being utilized in traditional healthcare systems ${ }^{6}$. Currently, research is trending on the use of natural medicinal plants for several reasons; safety, availability and affordability ${ }^{7}$. According to $\mathrm{WHO}, 15 \%$ out of 300000 plant species around the world have been tested for the pharmacological activity. Interestingly, around $25 \%$ of new medicines have been manufactured from natural resources such as herbal medicines ${ }^{8}$. Malaysia is a tropical country that is rich with medicinal plant species. For example, 1300 and 7411 plant species have been registered in Peninsular Malaysia and Sabah, respectively. Malaysia is one of the world's 12 megadiverse countries which are characterized by the highest endemism. At least a quarter of tree flora is not available anywhere in the world, and a lot of other species and herbaceous flora are unique. Around 2000 species of medicinal plant are recorded to own health benefit properties in Malaysia ${ }^{8}$. Eurycoma longifolia jack is a tropical medicinal plant, is a member of Simaroubaceae family, and is widely distributed in Malaysia ${ }^{9}$, Thailand, India and Vietnam ${ }^{10}$.

Together with tin and bird's nest, Eurycoma longifolia Jack is one of three national treasures of Malaysia. Its root has many biological functions like anti-fatigue, male testosterone level improvement hypertension and fever treatment ${ }^{10}$. Eurycoma

Cite this article: Yaseen MR, Faisal GG, Fuaat AA, Affandi KA, Alallam B, Nasir MHM. Preparation of Euyrycoma Longifolia Jack (E.L) Tongkat Ali (Ta) Root Extract Hydrogel for Wound Application. Pharmacogn J. 2021;13(6): 1456-1463. 
longifolia Jack plant grows naturally in Asia due to convenient climate and biodiversity richness ${ }^{9}$. Eurycoma longifolia Jack has been proved in many studies of having several classes of secondary metabolites. More than 65 bioactive constituents have been separated and characterized ${ }^{11}$ mostly from the extracts of Eurycoma Longifolia jack root $^{12}$. According to reports of several studies of phytochemical screening of Eurycoma longifolia Jack root extracts have shown the existence of phenolic compounds, flavonoids, terpenoids, alkaloids, cardiac glycosides and proteins ${ }^{13}$. The main compounds in Eurycoma longifolia Jack are quassinoids, terpenoids, alkaloids ${ }^{10}$, flavonoids, muccopolysaccharides, steroids, glycoproteins, tannins and squalene. The most abundant phytochemicals are present in the root are eurycomanon and eurycomanol, which are two highly oxygenated quassinoids ${ }^{9}$.

Wound-healing agents are commonly categorised as agents that have the ability to stimulate keratinocyte cell proliferation and differentiation, induce fibroblasts proliferation, accelerate collagen production or manifest antioxidant, anti-inflammatory and antimicrobial activities. Any agent that has two or more of these biological properties indicate that the agent is most likely to be a good healing agent ${ }^{14}$. The effect of phytochemicals in wound healing is reported and supported by many animal and clinical studies. Terpenoids accelerate wound healing cascade because of their antimicrobial and astringent properties; tannins are recorded to be effective detoxifying agents and suppress bacterial growth; flavonoids are powerful free radical scavengers and antioxidants ${ }^{15}$. Flavonoids are one of the most important bioactive compounds that are found in many medicinal plants which classified as wound healing agents in traditional uses. Currently, flavonoids are found in many of wound healing dressings and other formulations, which act through a synergistic or combined effect ${ }^{16}$. Flavonoids and polyphenols (inhibit the synthesis of prostaglandins) have antimicrobial and anti-inflammatory effects. Glycosides possess antimicrobial, antioxidant, anti-inflammatory, analgesic, immunomodulatory and antitumor activities. Thus, the availability of phytochemicals in the crude extract like flavonoids, saponins, terpenoids, phenolic compounds, tannins and glycosides may participate to wound healing activities individually or synergistic effects ${ }^{15}$.

The global market for herbal products is rapidly developing and anticipated to reach 115,000 million US $\$$ in 2020 , whereas the trade of medicinal plants will continue to progress with annual growth rates of $15-25 \%$. This increasing in the demand for plant-based products has led to an adulteration. Microscopic examination is the most commonly used method for identification and authentication of herbal medicines. Microscopic techniques examine the structural and cellular features of herbs to determine their botanical origin ${ }^{17}$.

Optimal topical wound agents must be safe, non-toxic and biocompatible. Because of the limitations and the high cost of synthetic wound healing agents, the seeking for substitutional ways or drugs, especially from medicinal plants, is the key of importance. Medicinal plants for stimulation wound healing are attractive options due to their safety and availability ${ }^{18}$.

Different categories of biomaterials have been emerged for wound healing applications, such as foams, ointments, gauze, transparent films, hydrocolloids, micro/ nanofibers, and hydrogels. Among them, hydrogel offers promising benefits, such as keeping the wound moist, high-water uptake and retention, no wound adherence, stimulating autolysis debridement, and promoting epithelial migration and granulation. Furthermore, epithelialization in moist wound occurs at double the rate in comparison with a dry wound, this is according to the moist wound healing theory. Thus, topical application of hydrogels can be useful for the wound healing process. natural, synthetic, and semi-synthetic polymer with diverse cross-linking methods could be used in hydrogel preparation ${ }^{19}$. Hydrogels are essential due to their biocompatibility and their capacity to sponge up the fluids and debris from injured areas ${ }^{20}$. Gels have better potential as a vehicle to deliver drug topically because they are non-sticky in comparison to ointment, demand low energy during preparation, have aesthetic value and they are stable ${ }^{21}$.

This study aimed to authenticate the roots and extract them, to identify the Ic50 by MTT assay, and to determine the safe dose of extract in the hydrogel preparation, which will be used to study the wound healing potentials of Eurycoma longifolia Jack root extract.

\section{MATERIALS AND METHODS}

\section{Material}

Ethanol 95\%, denatured was from HmbG (Hamburg, Germany) and Cellulose thimble was purchased from Whatman (Maidstone, United Kingdom). Xanthan gum was purchased from EvaChem (Selangor, Malaysia). Glycerol was from Merck (Massachusetts, United States), Ethylenediaminetetraacetic acid EDTA, 99\%pure was purchased from ACROS Organics (Massachusetts, United States). Phosphate Buffered Saline (PBS) pH $7.4(1 \times)$ (without $\mathrm{Ca} 2+$ and $\mathrm{Mg} 2+$ ) and Dimethyl sufoxide (DMSO) were from Sigma Aldrich (Missouri, USA). Dulbecco's Modified Eagle Medium (DMEM) and Foetal bovin Serum (FBS) were purchased from Gibco Life Technologies (California, USA). Tetrazolium salt (3-(4,5-dimethylthiazol-2yl)- 2,5-diphenyltetrazolium bromide (MTT) was purchased from Molecular Probes, Life Technologies (California, USA).

\section{Collection, Authentication, and Preparation of Plant Material}

$2 \mathrm{Kg}$ of Eurycoma longifolia Jack commonly known Tongkat Ali (TA) root was purchased from a certified supplier in Kuantan, Pahang, Malaysia. The plant was collected, from Pahang forests. Then, the root was authenticated in Natural Medicinal Products Centre, Kulliyyah of Pharmacy, IIUM Kuantan campus, Pahang, Malaysia, by Microscopic Physical Examination. The roots were given voucher specimen number in Herbarium, KOP, IIUM. The voucher specimens were submitted to the Herbarium of kulliyyah of pharmacy IIUM, Voucher specimen no.: PIIUM 0288-1.

\section{Microscopical Examination of Crude Herbal Drug of The Root}

The part of the plant that was used for this study is Taproot slices, these slices labelled as TA and they were examined. The sample was ground into a fine powder and kept in an airtight container until further test. Microscopical characteristics of the powdered crude herbal drug sample, TA were determined by using methylene blue for general observation while the starch granules were identified by using Lugol's iodine solution. The images were digitally captured with a Leica DM750 microscope (LeicaTM-Wetzlar, Germany) by using a video camera plugged to a computer utilizing the Leica Application Suite (LAS) EZ (LeicaTM-Wetzlar, Germany) software for image analysis. All pictures were taken with 400x magnification.

\section{Methods of Extraction}

A quantity of $2 \mathrm{Kg}$ of Eurycoma longifolia Jack TA roots was extracted by Soxhlet extraction using $100 \%$ ethanol alcohol and thimble. The roots of TA were ground by using Waring blender into a coarse size and $1944.7 \mathrm{~g}$ was obtained. The effective compounds of the sample were extracted with $100 \%$ ethanol at its boiling point at 60 to $65^{\circ} \mathrm{C}$ for about 24 hours. Then, under vacuum and minimized pressure the extracts were dried by rotary evaporator at $60^{\circ} \mathrm{C}$ and pressure of 175 mbar. 


\section{Cell Culture}

Human Primary Gingival Fibroblast cells (PCS-201-018") was purchased from American Type Culture Collection (ATCC) and were cultured in the recommended complete growth medium. The cells were kept at $37^{\circ} \mathrm{C}$ in a humidified atmosphere with $5 \%$ of $\mathrm{CO}_{2}$ atmosphere.

\section{Cell Viability Assay}

Cell viability was identified to evaluate the in vitro cytotoxicity of Eurycoma longifolia ethanolic extract to human primary gingival fibroblast cells by determining the metabolic activity of treated cells compared to control cells via MTT assay. Briefly, human primary gingival fibroblast cells were seeded into 96-well plate at a density of 1.0 $\times 10^{5}$ cells $/ \mathrm{mL}$ overnight. After $24 \mathrm{~h}$, the media was removed and cells were kept in $100 \mu \mathrm{L}$ of media suspended with various concentrations of the extract $(3.125,6.25,25,50,125,225$, and $400 \mu \mathrm{g} / \mathrm{mL})$. After 24 $\mathrm{h}$ of extract exposure, media was replaced with $80 \mu \mathrm{L}$ phenol red-free complete media and $20 \mu \mathrm{L}$ of MTT reagent $(5 \mathrm{mg} / \mathrm{mL})$. After $4 \mathrm{~h}$, the medium was removed, and $100 \mu \mathrm{L}$ of DMSO was added to each well. The plate was kept at room temperature until crystals were melted, and the optical densities were recorded at $570 \mathrm{~nm}$ using a Tecan Infinite 200 microplate reader (Tecan Austria GmbH, Grodig, Austria). Percent of relative cell viability were calculated, after blank subtraction, by dividing the optical density of treated cells by the untreated ones. The negative control was untreated cells. The Ic50 was calculated using GraphPad Prism software.

Preparation of Eurycoma longifolia Jack root extract TA in a suitable dosage form (Hydrogel) for wound application

Ethanol extract of Eurycoma longifolia Jack is insoluble in oil so it cannot be prepared in the form of ointment. This medicinal plant is water based so it can be applied in the form of hydrogel for wound healing study. Natural polysaccharide xanthan gum was used as polymer to prepare Eurycoma longifolia Jack TA hydrogel. The hydrogel was prepared using various concentrations of the gum $(1 \%, 2 \%$ and $3 \%)$ as it is mentioned in Table 1. Briefly EDTA powder was dissolved in 100 $\mathrm{mL}$ distilled water, followed by glycerine. Ethanol extract of the root of Eurycoma longifolia Jack Tongkat Ali was added to the solution while stirring at concentration of $120 \mu \mathrm{g} / \mathrm{mL}$. Sodium sorbate was added and finally xanthan gum was added. Then the hydrogel was left until full hydrate. Comparative Evaluation of Eurycoma Longifolia Jack root Extract TA Hydrogel Appearance, $\mathrm{pH}$ and spreadability

The above formulated hydrogels containing Ethanol extract of Eurycoma longifolia Jack TA root were subjected to evaluation for the following parameters:

\section{pH}

The $\mathrm{pH}$ of the hydrogels was measured using electrode type $\mathrm{pH}$ meter (brand, METTLER TOLEDO). The glass electrode was calibrated with the solutions ( $\mathrm{pH}$ of 4.00 and 7.00) determined for the equipment ${ }^{22}$.

Table 1: The composition and concentration of Eurycoma longifolia Jack TA root extract hydrogel formulations.

\begin{tabular}{lccc|}
\hline Ingredients & F1 & F2 & F3 \\
\hline Eurycoma Longifolia Jack Tongkat ali extract (mg) & 12 & 12 & 12 \\
Tetrasodium EDTA powder (mg) & 13 & 13 & 13 \\
Glycerine (mg) & 120 & 120 & 120 \\
Potssium sorbate (mg) & 0.8 & 0.8 & 0.8 \\
Xanthan gum (mg) & 1000 & 2000 & 3000 \\
Distilled water (ml) & 100 & 100 & 100
\end{tabular}

\section{Table 2: Values of evaluation parameters of the prepared gel.}

\begin{tabular}{|cccc|}
\hline Batch no & PH & $\begin{array}{c}\text { Spreadability } \\
(\text { g.cm/min) }\end{array}$ & Homogeneity \\
\hline F1 & $7.24 \pm 0.22$ & $265.55 \pm 1.88$ & Good \\
F2 & $6.91 \pm 0.03$ & $233.47 \pm 2.39$ & Good \\
F3 & $6.88 \pm 0.01$ & $132.80 \pm 1.27$ & Good \\
\hline
\end{tabular}

\section{Spreadability ${ }^{23}$}

Hydrogel spreadability was determined by spreading of $0.1 \mathrm{~g}$ of the herbal gel formulation on $2 \mathrm{~cm}$ diameter circle premarked on a glass plate and then a second glass plate was utilized. A weight of $100 \mathrm{~g}$ was placed on the upper glass plate for $5 \mathrm{~min}$. The diameter of the circle after spreading the hydrogel was determined. Spreadability was determined by using the following formula:

\section{$\mathrm{S}=\mathrm{M} \times \mathrm{L} / \mathrm{T}$}

Where $\mathrm{S}$ is spreadability, $\mathrm{M}$ is the weight tied to upper slides, $\mathrm{L}$ is the length of the glass slide and $\mathrm{T}$ is time taken in minutes.

\section{Homogeneity ${ }^{24}$}

After the gels have been put in the container, all prepared gels were examined for homogeneity by visual observation. They were examined for their colour, appearance and homogeneity. All the prepared gels were visually evaluated for the presence of particles and fibres (Table 2).

\section{Statistical Analysis}

Minitab 19 were used to analyze the data using one-way ANOVA and followed by Tukey's test. Data were performed in triplicate and represented as mean \pm standard deviation $(\mathrm{n}=3)$, considering $p<0.05$ as an indication for statistical significance.

\section{RESULTS}

\section{Microscopical Examination of Crude Herbal Drug of The Root}

TA present the same visual characters as that of E.longifolia Jack tap root, which is Yellowish white in color, woody, slightly pungent smell and very bitter in taste (Figure 1$)^{25}$. For the microscopic examination of the crude herbal drug sample, TA presents the same microscopical characters to that of E. longifolia tap root ${ }^{26}$ as: pitted vessel with bordered pores fragments (Figure 2); abundant of starch granules, mostly are simple spherical or oval in shape with transverse-Y-shaped and other fissures (Figure 3); prism-shaped calcium oxalate crystals (Figure 4); thin-walled fibres (Figure 5); thick reticulated vessels (Figure 6); thickwalled cork cells, isodiametric in shape and are found associated with fibres (Figure 7); and thin-walled parenchyma cells (Figure 8).

\section{Extraction of the roots of Eurycoma longifolia Jack}

The extract was brownish and viscous in nature. The weight of the final extract was $45.3 \mathrm{~g}$.

\section{Cell Viability Assay}

MTT assay were used to determine human primary gingival fibroblast cell viability. Eight concentrations of the extract were studied to assess the safety of the TA ethanolic extract. Results suggested that extract showed dose-dependent effect (Figure 9). Extract-treated cells viabilities at concentration $>6.25 \mu \mathrm{g} / \mathrm{mL}$ were found to be significantly lower than that of untreated cells. The $\mathrm{Ic}_{50}$ was calculated, and it was $118.5 \mu \mathrm{g} / \mathrm{mL}$ ( $\mathrm{Ic}_{50}$ range was from 94.39 to $146.9 \mu \mathrm{g} / \mathrm{mL}, \mathrm{R}^{2}=0.9219$ ) (Figure 10). From this result, the concentration of treatments below $\mathrm{IC}_{50}$ was considered as safe to be used for further study. 


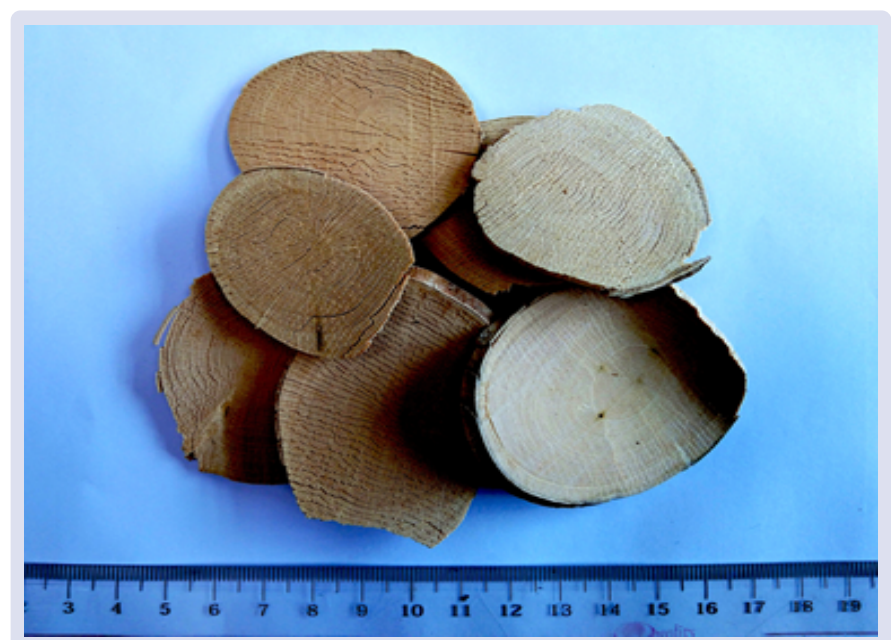

Figure 1: Photo of Plant/sample (taproot slices).

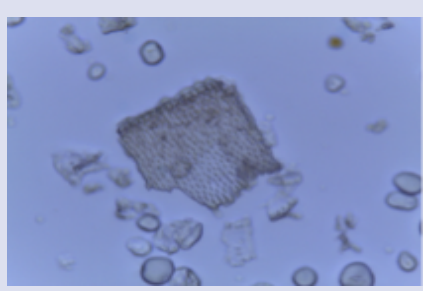

(a)

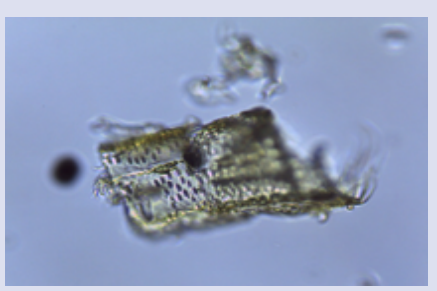

(b)
Figure 2: Pitted vessel with bordered pores fragments.

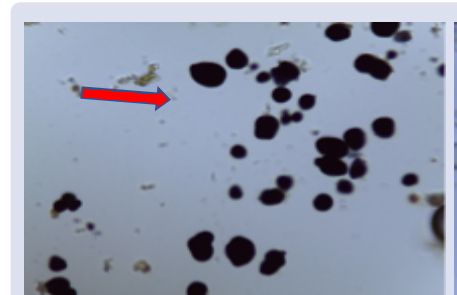

(a)

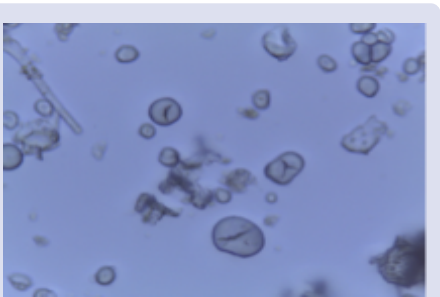

(b)
Figure 3: (a) Starch granules spherical and oval shaped starch granules (stained blue black with iodine solution). (b) Starch granules with transverse and Y-shaped fissures.

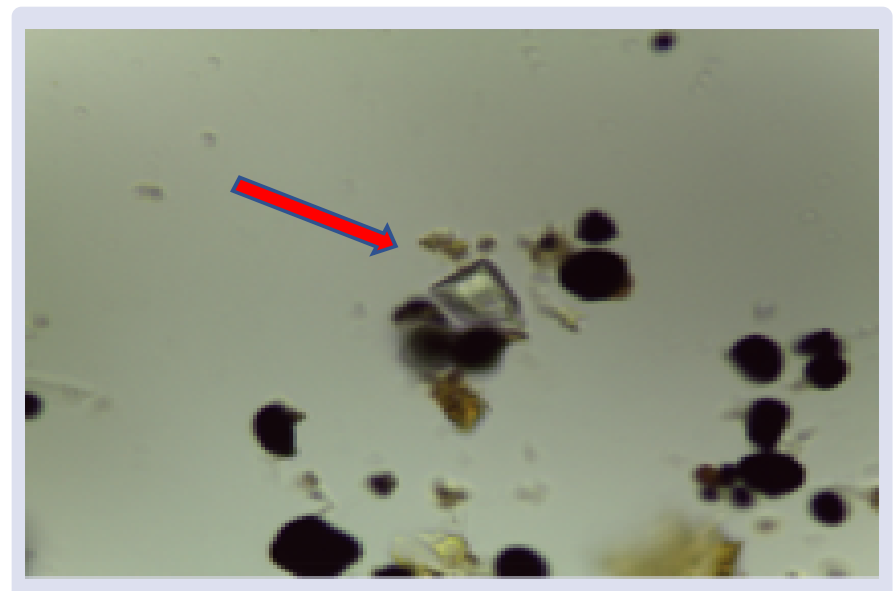

Figure 4: Prism-shaped calcium oxalate crystal.
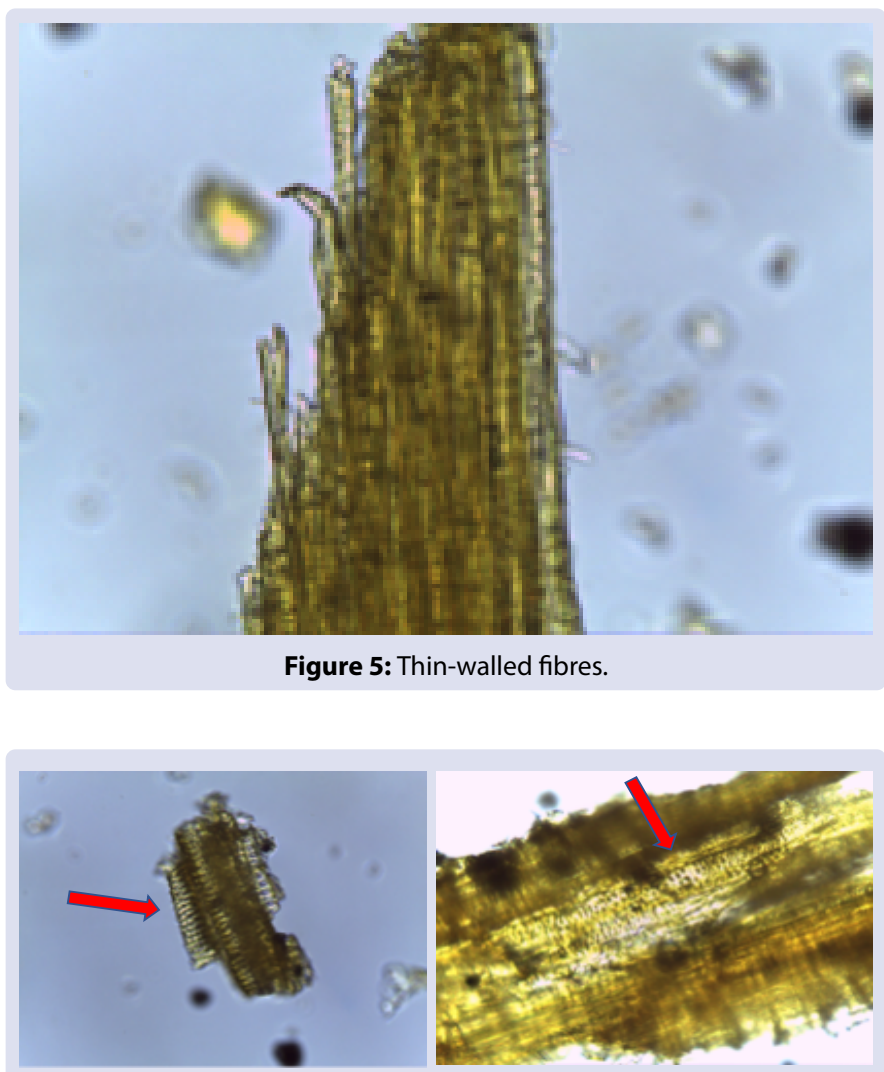

Figure 6: Thick reticulated vessels.
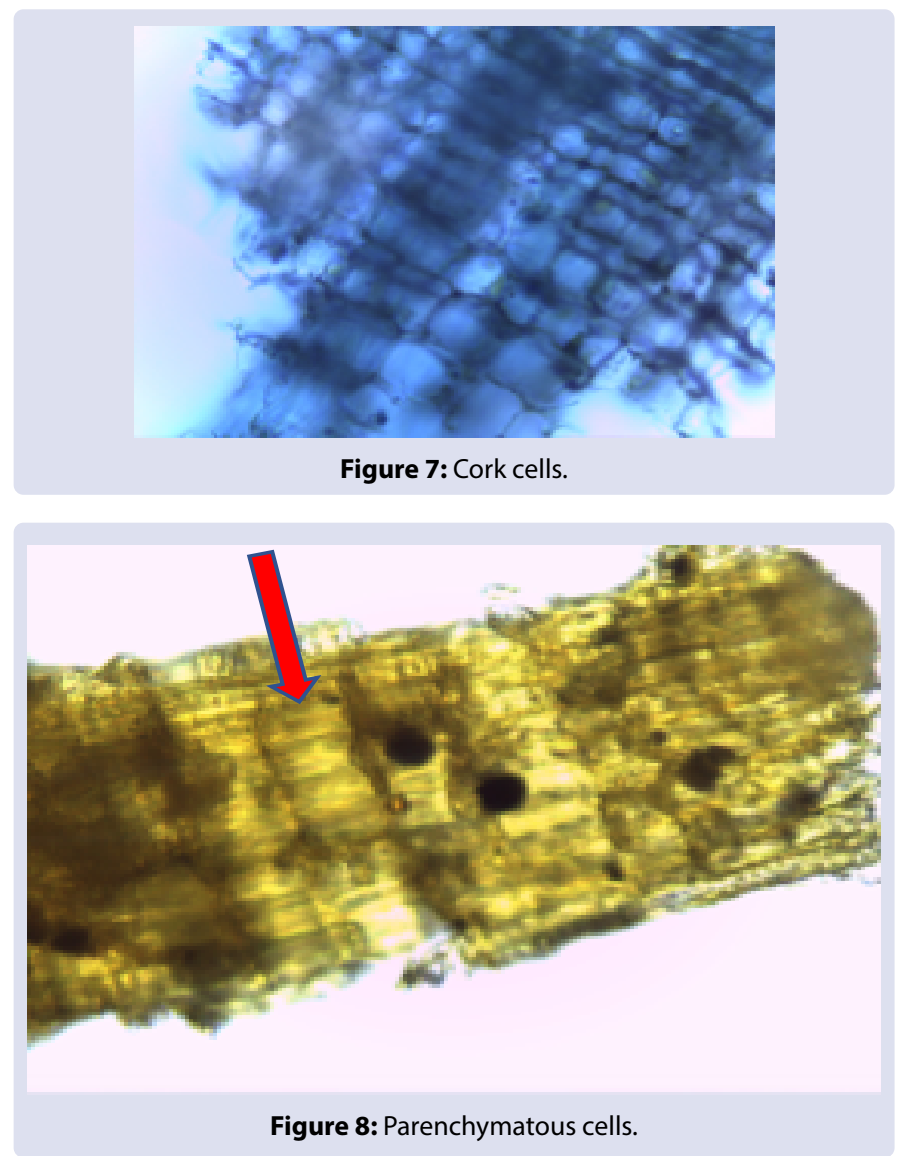


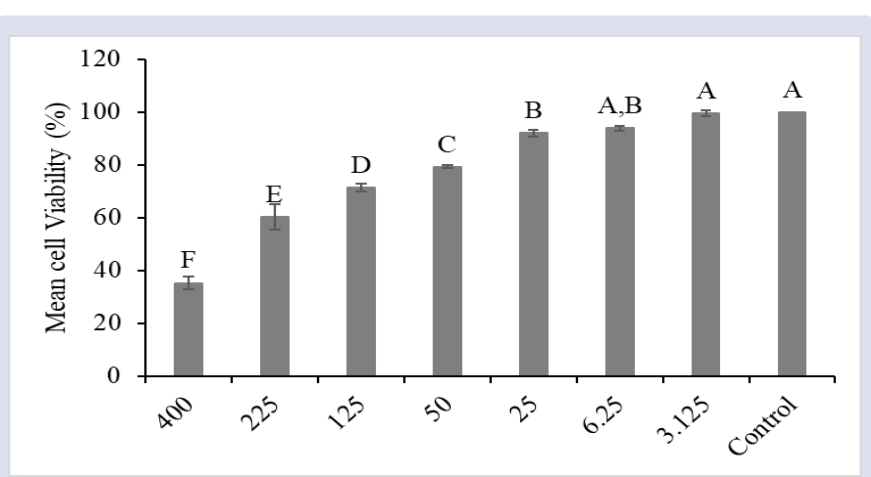

Figure 9: The percentage of human primary gingival fibroblast cell viability treated with ethanolic extract of Eurycoma longifolia at various concentrations for 24 hours. Letters denote significance; whereby groups do not share letters are significantly different $(p<0.05)$.

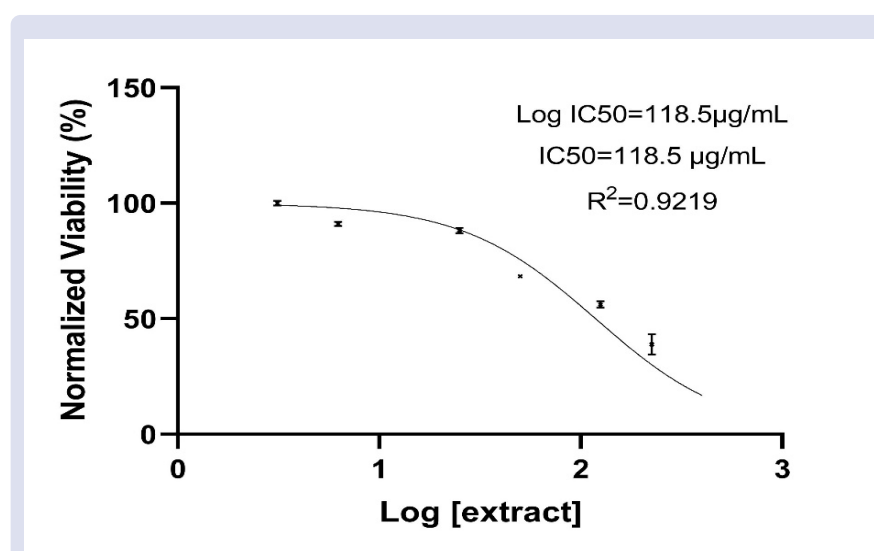

Figure 10: The plot generated from GraphPad Prism software showing the $\mathrm{Ic}_{5}$

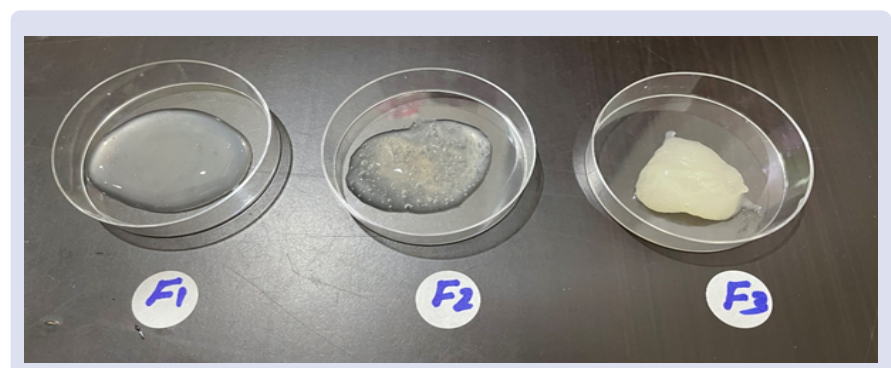

Figure 11: Colour and appearance of the prepared hydrogel.

\section{Preparation and Evaluation of Eyrycoma longifolia Jack Tongkat Ali root extract hydrogel for wound application}

Three hydrogels were prepared F1, F2, and F3 having $1 \%, 2 \%$, and $3 \%$ xanthan gum. All prepared gels exhibited a good homogeneity with absence of lumps, while they were varied in their colour and appearance; F1 showed clear transparent hydrogel; F2 showed a light yellow slightly opaque hydrogel and F3 showed yellow opaque hydrogel (Figure 11). The opaqueness was increased as xanthan gum concentration increased. The $\mathrm{pH}$ and spreadability of the prepared hydrogel were decreased as the concentration of xanthan gum was increased (Table 2). No change in colour, homogeneity and appearance was observed for the prepared hydrogel over three weeks of storage at $4{ }^{\circ} \mathrm{C}, 25^{\circ} \mathrm{C}$ and $40^{\circ} \mathrm{C}$. similarly, there was no significant change in $\mathrm{pH}$ or spreadability of all formulation until week 2 of storage; however, a significant decrease in them was reported at week 3 of storage at all temperatures.

\section{DISCUSSION}

Eurycoma longifolia Jack Tongkat Ali roots are the most important part of the plant, many studies have shown that the root has anti-malarial, aphrodisiac, anti-osteoporosis and anti-inflammatory effects ${ }^{27}$. Recently many studies have proved that the ethanol extract of Tongkat Ali roots possesses antioxidant and antibacterial properties against strains $B$. cereus, S.aureus, S. typhi ${ }^{28}$ and Streptococcus mutans ${ }^{29}$. Moreover, ethanol-based Eurycoma longifolia Jack root extract exhibited positive antifungal activity against A.fumigatus and C.albicans ${ }^{29,30}$. For the antiinflammatory activity of Eurycoma longifolia Jack root, 70\% ethanol extract of E. longifolia Roots displayed anti-inflammatory effects due to the presence of phenolic acids, coumarins, triterpenoids, and terpenes. These phytochemicals have shown considerable inhibitory effects on LPS-induced protein expression of NF-kB, IL-6, and iNOS in the NF$\mathrm{kB}$ signalling pathway ${ }^{10}$. In Vietnam, they have used alcoholic extracts of Eurycoma longifolia Jack roots for the management and treatment of rheumatism, since this medicinal plant contains alkaloids, flavonoids and quassinoids, which are potent NF-kB inhibitors (anti-inflammatory activity) ${ }^{31}$. All these pharmacological effects are attributed to the availability of bioactive compounds, which are concentrated in the root. According to the reports of several studies of phytochemical screening of Eurycoma longifolia Jack root extracts have shown the presence of phenolic compounds, flavonoids, terpenoids, alkaloids, cardiac glycosides and proteins ${ }^{13}$. The main compounds in Eurycoma longifolia Jack are quassinoids, terpenoids, alkaloids ${ }^{10}$, flavonoids, mucopolysaccharides, steroids, glycoproteins, tannins and squalene 9 .

Many studies have displayed those phytochemicals having great potential for enhancing and accelerating wound healing process because they are polytropic sources as anti-inflammatory, antioxidant and antimicrobial agents ${ }^{32}$. Alcoholic extracts of E. longifolia roots have potent anti-inflammatory and antioxidant effects ${ }^{10,31}$, as well as antimicrobial effects $28,29,30$ which are the main mechanisms for medicinal plants to be effective wound healing agents. This means that the alcoholic extract of Eurycoma Longifolia Jack root has a strong potential to be developed into a wound healing agent that can be used topically, like a hydrogel.

In this study, the roots were authenticated, extracted and its $\mathrm{IC}_{50}$ was determined for the preparation of Eurycoma longifolia Jack hydrogel for further in vivo wound healing study. The roots of Eurycoma longifolia Jack were authenticated by microscopic examination. This technique has long been used to recognize herbal products in many countries due to its advantages of a small quantity of sample required, rapidity, accuracy, simplicity, and affordability. Histochemical methods have been used to discover the features of tissue structure and cellular characteristics that can be used as markers for identification of the species. Methylene blue was used for general observation which revealed one of the characteristics of Eurycoma longifolia Jack root, which was pitted vessel with bordered pores fragments. Lugol's iodine solution was used to identify the starch granules, calcium oxalate crystal, fibres and the cells. The microscopic examination of TA sample revealed the same characteristics of Eurycoma longifolia Jack tap roots, so the crude herbal drug sample TA is authenticated as Eurycoma longifolia root based on its microscopical characters. These cellular and structural characteristics can be used in verification of plant authenticity and in detection of adulterations.

Microscopic authentication indicates to the analysis of structural, cellular and molecular characteristics of herbal products using various kinds of microscopy ${ }^{17}$. Accurate botanical identification may confirm the safety of using of herbal based products. Without accurate identification, the safer employ of quality products cannot be guaranteed ${ }^{33}$.

The cytotoxic effect of ethanolic extract of the TA roots on cultured human primary gingival fibroblasts cell line was determined to 
Table 3: Evaluation parameters of the formulated hydrogel over period of three weeks.

\begin{tabular}{|c|c|c|c|c|c|c|c|c|c|c|}
\hline \multicolumn{2}{|l|}{ Duration } & \multicolumn{3}{|l|}{ F1 } & \multicolumn{3}{|l|}{ F2 } & \multicolumn{3}{|l|}{ F3 } \\
\hline \multirow{7}{*}{ Day 1} & Test & $4^{\circ} \mathrm{C}$ & $25^{\circ} \mathrm{C}$ & $40^{\circ} \mathrm{C}$ & $4^{\circ} \mathrm{C}$ & $25^{\circ} \mathrm{C}$ & $40^{\circ} \mathrm{C}$ & $4^{\circ} \mathrm{C}$ & $25^{\circ} \mathrm{C}$ & $40^{\circ} \mathrm{C}$ \\
\hline & $\mathrm{PH}$ & $7.22 \pm 0.22$ & $7.24 \pm 0.22$ & $7.28 \pm 0.22$ & $6.92 \pm 0.03$ & $6.91 \pm 0.03$ & $6.94 \pm 0.03$ & $6.90 \pm 0.01$ & $6.88 \pm 0.01$ & $6.84 \pm 0.01$ \\
\hline & $\begin{array}{l}\text { Spreadability } \\
\text { (g.cm/min) }\end{array}$ & $265.88 \pm 1.23$ & $265.55 \pm 1.88$ & $266.18 \pm 1.22$ & $232.06 \pm 2.83$ & $233.47 \pm 2.39$ & $232.12 \pm 2.72$ & $132.23 \pm 3.43$ & $132.80 \pm 1.27$ & $132.89 \pm 3.98$ \\
\hline & Homogenicity & Homogenou & & & Homogenous & & & Homogenous & & \\
\hline & Colour & transparent & & & light yellow & & & light yellow & & \\
\hline & Appearance & Clear and tra & anslucent & & Slightly opaqu & & & opaque & & \\
\hline & $\mathrm{PH}$ & $7.21 \pm 0.22$ & $7.22 \pm 0.22$ & $7.25 \pm 0.22$ & $6.90 \pm 0.03$ & $6.92 \pm 0.03$ & $6.93 \pm 0.03$ & $6.88 \pm 0.01$ & $6.86 \pm 0.01$ & $6.83 \pm 0.01$ \\
\hline \multirow{4}{*}{ Week 2} & $\begin{array}{l}\text { Spreadability } \\
(\mathrm{g} . \mathrm{cm} / \mathrm{min})\end{array}$ & $266.66 \pm 1.22$ & $265.57 \pm 1.09$ & $267.01 \pm 1.13$ & $233.33 \pm 1.02$ & $232.09 \pm 1.00$ & $233.70 \pm 0.92$ & $133.33 \pm 1.43$ & $132.77 \pm 2.72$ & $133.88 \pm 2.53$ \\
\hline & Homogenicity & Homogenou & & & Homogenous & & & Homogenous & & \\
\hline & Colour & light yellow & & & light yellow & & & light yellow & & \\
\hline & Appearance & Clear and tra & anslucent & & Slightly opaqu & & & opaque & & \\
\hline \multirow{5}{*}{ Week 3} & $\mathrm{PH}$ & $5.97 \pm 0.04$ & $6.29 \pm 0.33$ & $6.11 \pm 0.01$ & $5.83 \pm 0.03$ & $6.64 \pm 0.01$ & $6.7 \pm 0$ & $5.97 \pm 0.04$ & $5.12 \pm 0.03$ & $4.90 \pm 0.01$ \\
\hline & $\begin{array}{l}\text { Spreadability } \\
\text { (g.cm/min) }\end{array}$ & $236.66 \pm 2.43$ & $250 \pm 1.92$ & $266.66 \pm 2.65$ & $183.33 \pm 2.65$ & $200 \pm 3.54$ & $216.66 \pm 3.65$ & $150 \pm 3.61$ & $152 \pm 2.11$ & $153.33 \pm 2.43$ \\
\hline & Homogenicity & Homogenou & & & Homogenous & & & Homogenous & & \\
\hline & Colour & transparent & & & light yellow & & & light yellow & & \\
\hline & Appearance & Clear and tra & anslucent & & Slightly opaqu & & & opaque & & \\
\hline
\end{tabular}

incorporate the safe dose of extract to be loaded into hydrogel. The reason for the extensive usage of herbal based products has been partially known by the fact that these medicinal plants are of natural source and they are regarded safe to consume in comparison to synthetic products. But, not all of these herbal products are safe to use. Some Herbal products associated with unfavourable effects have been recorded and continue to attract researchers' attention ${ }^{34}$.

Therefore, according to the result of MTT assay the maximum safety dose of ethanol extract of Eurycoma longifolia Jack to be incorporated in the hydrogel for wound application is $120 \mathrm{ug} / \mathrm{mL}$.

Direct application of herbal extract to the affected wound cannot give the favourable effect since it does not stay long on the injured skin of tested animals ${ }^{15}$. Ethanol extract of Eurycoma Longifolia Jack is insoluble in oil, so it cannot be prepared in the form of ointment, but it is readily soluble in water, hence it can be delivered in the form of hydrogel for wound application. Hydrogels are hydrophilic polymer networks that can sponge up a significant number of fluids, which is one of the important advantages of hydrogels for herbal medicines delivery. Some hydrogels have also exhibited high drug loading efficiency and have attracted extensive studies in pharmaceutical industry. The essential constituents of hydrogels are polymers, which can be natural or synthetic in origin. The promising prospect of using hydrogels to deliver medicinal plants has been strongly supported by many studies ${ }^{35}$.

In this study, three hydrogels (F1, F2 and F3) were prepared using different concentrations of xanthan gum (the polymer of this hydrogel) $(1 \%, 2 \%$ and $3 \%)$ with same concentration of the extract, which was $0.12 \% \mathrm{w} / \mathrm{v}$. All three preparations were assessed for their physical appearance, $\mathrm{pH}$, and spreadability. F3 was opaque due to increasing the concentration of xanthan gum. Table 3 shows that F2 was having the most suitable $\mathrm{pH}$ for wound healing which was 6.9 neutral slightly acidic. The Value of $\mathrm{pH}$ within the wound has been shown to affect directly and indirectly all biochemical events which are crucial for healing. Particularly, $\mathrm{pH}$ has been shown to have a pivotal role to play in the wound healing as $\mathrm{pH}$ is significantly affects on underlying pathophysiology, biochemistry, immunology, and microbiology. Historically, it has been known that the low value of $\mathrm{pH}$, like is found on normal skin, is more favourable for healing the wound. Generally, lowering $\mathrm{pH}$ has led to improving in the antimicrobial activity of some antimicrobials ${ }^{36}$. The $\mathrm{PH}$ of human skin is between 4.6 and 6.0. which is slightly acidic ph. This $\mathrm{pH}$ range contributes to the protection of the skin surface against fungi and bacteria ${ }^{37}$. A previous study had investigated the effects of $\mathrm{pH}$ on human fibroblasts and keratinocytes and it was found that both cells can tolerate a wide range of $\mathrm{pH}$ very well ${ }^{21}$.

The value of spreadability indicates the degree of required shear to apply the gel ${ }^{22}$. F1 shown good spreadability as compared to F2 and F3. The spreading of the gel is useful in the identical application of the gel to the skin, so the prepared gels must have a good spreadability and meet the good quality in topical application. Moreover, this is taken in to account for patient's expectation with the treatment ${ }^{23}$. The decrease of spreadiapility over preparation is due to increasing the polymer viscosity. Moreover, the decreasing in spreadability of the hydrogel over the storage time could be due to the losing of some water from the gel. From the evaluation parameters, it was apparent that the hydrogel prepared with $2 \%$ xanthan was found to be superior to the hydrogels prepared with $1 \%$ and $3 \%$ xanthan gum in terms of $\mathrm{pH}$ and spreadability. The stability data of the hydrogel have indicated that the hydrogel could be stored at either temperature as there was no significant changes between them. Hence it was decided to store it at 4 ${ }^{\circ} \mathrm{C}$ for maximum two weeks to conduct the animal study. For animal study F2 is more suitable for application as the topical base should spread easily without too much drag and should not produce greater friction in the rubbing process. While $\mathrm{F} 1$ is too watery so it will run off easily from the wound, as the rat is very active and move around, F3 is too viscose and thick so we cannot apply it easily on the fresh wound because it will need extra rubbing and this may be will disturb the wound healing process and environment and the hydrogel should be prepared weekly to keep its good characteristic, fresh and effective.

\section{CONCLUSION}

Ethanol extract of Eurycoma longifolia Jack TA is readily soluble in water so this medicinal plant is water based, hence it can be applied in the form of hydrogel for wound healing study. According to the results of preparation and evaluation parameters of 3 prepared TA hydrogels, TA hydrogel with $2 \%$ xanthan gum is the most suitable for the wound application for further animal study since its $\mathrm{PH}$ and spreadablity is appropriate for wound healing study. 


\section{REFERENCE}

1. Ali, A., Garg, P., Goyal, R., Kaur, G., Li, X., Negi, P., Valis, M., Kuca, K., \& Kulshrestha, S. (2021). A novel herbal hydrogel formulation of moringa oleifera for wound healing. Plants, 10(1), 1-13. https://doi. org/10.3390/plants10010025

2. Chouhan, D., Dey, N., Bhardwaj, N., \& Mandal, B. B. (2019). Emerging and innovative approaches for wound healing and skin regeneration: Current status and advances. Biomaterials, 216(May), 119267. https://doi.org/10.1016/j.biomaterials.2019.119267

3. Lordani, T. V. A., de Lara, C. E., Ferreira, F. B. P., de Souza Terron Monich, M., da Silva, C. M., Lordani, C. R. F., Bueno, F. G., Teixeira, J. J. V., \& Lonardoni, M. V. C. (2018). Therapeutic effects of medicinal plants on cutaneous wound healing in humans: a systematic review. Mediators of Inflammation, 2018. https://doi. org/10.1155/2018/7354250

4. Tottoli, E. M., Dorati, R., Genta, I., Chiesa, E., Pisani, S., \& Conti, B. (2020). Skin wound healing process and new emerging technologies for skin wound care and regeneration. Pharmaceutics, 12(8), 1-30. https://doi.org/10.3390/pharmaceutics12080735

5. Shedoeva, A., Leavesley, D., Upton, Z., \& Fan, C. (2019). Wound healing and the use of medicinal plants. Evidence-Based Complementary and Alternative Medicine, 2019(Figure 1). https:// doi.org/10.1155/2019/2684108

6. Kumar Srivastava, A. (2018). Significance of medicinal plants in human life. In Synthesis of Medicinal Agents from Plants. Elsevier Ltd. https://doi.org/10.1016/b978-0-08-102071-5.00001-5

7. Sultana, N., Alsarhan, A., Al-Khatib, A., \& Kadir, M. (2014). Review on Some Malaysian Traditional Medicinal Plants with Therapeutic Properties. Journal of Basic \& Applied Sciences, 10(April), 149-159. https://doi.org/10.6000/1927-5129.2014.10.20

8. Izzany, F., Bakar, A., Fadzelly, M., Bakar, A., Abdullah, N., Endrini, S., \& Rahmat, A. (2018). A Review of Malaysian Medicinal Plants with Potential Antidiabetic. 2018.

9. Abubakar, B. M., Salleh, F. M., \& Wagiran, A. (2017). Chemical Composition of Eurycoma longifolia (Tongkat Ali) and the Quality Control of its Herbal Medicinal Products. Journal of Applied Sciences, 17(7), 324-338. https://doi.org/10.3923/jas.2017.324.338

10. Ruan, J., Li, Z., Zhang, Y., Chen, Y., Liu, M., Han, L., Zhang, Y., \& Wang, T. (2019). Bioactive Constituents from the Roots of Eurycoma longifolia. Molecules, 24(17), 1-16. https://doi. org/10.3390/molecules24173157

11. Li, C. H., Liao, J. W., Liao, P. L., Huang, W. K., Tse, L. S., Lin, C. H., Kang, J. J., \& Cheng, Y. W. (2013). Evaluation of acute 13-week subchronic toxicity and genotoxicity of the powdered root of Tongkat Ali (Eurycoma Longifolia Jack). Evidence-Based Complementary and Alternative Medicine, 2013. https://doi. org/10.1155/2013/102987

12. H. Yusuf *. (2019). THE ACTIVITY OF EURYCOMANONE DERIVATIVES ON CANCER CELL LINES H. Yusuf* 1 , D. Satria 2 and Zulkarnain 3 Department. ISSN 2502-3632 (Online) ISSN 2356-0304 (Paper) Jurnal Online Internasional \& Nasional Vol. 7 No.1, Januari Juni 2019 Universitas 17 Agustus 1945 Jakarta, 53(9), 1689-1699. https://doi.org/10.13040/IJPSR.0975-8232.10(6).2947-50

13. Khanam, Z., Wen, C. S., \& Bhat, I. U. H. (2015). Phytochemical screening and antimicrobial activity of root and stem extracts of wild Eurycoma longifolia Jack (Tongkat Ali). Journal of King Saud University - Science, 27(1), 23-30. https://doi.org/10.1016/j. jksus.2014.04.006

14. Boakye, Y. D., Agyare, C., Ayande, G. P., Titiloye, N., Asiamah, E. A., \& Danquah, K. O. (2018). Assessment of wound-healing properties of medicinal plants: The case of Phyllanthus muellerianus. Frontiers in Pharmacology, 9(AUG), 1-12. https://doi.org/10.3389/ fphar.2018.00945
15. Demilew, W., Adinew, G. M., \& Asrade, S. (2018a). Evaluation of the Wound Healing Activity of the Crude Extract of Leaves of Acanthus polystachyus Delile (Acanthaceae). Evidence-Based Complementary and Alternative Medicine, 2018. https://doi. org/10.1155/2018/2047896

16. Muhammad Shahzad Aslam. (2018). We are IntechOpen, the world ' s leading publisher of Open Access books Built by scientists, for scientists TOP $1 \%$. Intech. http://www.intechopen.com/books/ trends-in-telecommunications-technologies/gps-total-electroncontent-tec- prediction-at-ionosphere-layer-over-the-equatorialregion \% 0AInTec\% 0Ahttp://www.asociatiamhc.ro/wp-content/ uploads/2013/11/Guide-to-Hydropower.pdf

17. Ichim, M. C., Häser, A., \& Nick, P. (2020). Microscopic Authentication of Commercial Herbal Products in the Globalized Market: Potential and Limitations. Frontiers in Pharmacology, 11(June). https://doi. org/10.3389/fphar.2020.00876

18. Nguyen, V. L., Truong, C. T., Nguyen, B. C. Q., van Vo, T. N., Dao, T. T., Nguyen, V. D., Thi Trinh, D. T., Huynh, H. K., \& Bui, C. B. (2017). Anti-inflammatory and wound healing activities of calophyllolide isolated from Calophyllum inophyllum Linn. PLOS ONE, 12(10), 1-16. https://doi.org/10.1371/journal.pone.0185674

19. Salehi, M., Zamiri, S., Samadian, H., Ai, J., Foroutani, L., Ai, A., \& Khanmohammadi, M. (2021). Chitosan hydrogel loaded with Aloe vera gel and tetrasodium ethylenediaminetetraacetic acid (EDTA) as the wound healing material: in vitro and in vivo study. Journal of Applied Polymer Science, 138(16), 1-10. https://doi.org/10.1002/ app.50225

20. Ajith, G., Goyal, A. S., Rodrigues, F. C., \& Thakur, G. (2021). Natural polysaccharides for wound healing. In Food, Medical, and Environmental Applications of Polysaccharides (Issue February 2021). https://doi.org/10.1016/b978-0-12-819239-9.00019-1

21. Kruse, C. R., Singh, M., Targosinski, S., Sinha, I., Sørensen, J. A., Eriksson, E., \& Nuutila, K. (2017). The effect of pH on cell viability, cell migration, cell proliferation, wound closure, and wound reepithelialization: In vitro and in vivo study. Wound Repair and Regeneration, 25(2), 260-269. https://doi.org/10.1111/wrr.12526

22. Rajesh, B., Saumya, D., Dharmajit, P., \& Pavani, M. (2014). Formulation design and optimization of herbal gel containing albizia lebbeck bark extract. International Journal of Pharmacy and Pharmaceutical Sciences, 6(5), 111-114.

23. Dantas, M. G. B., Reis, S. A. G. B., Damasceno, C. M. D., Rolim, L. A., Rolim-Neto, P. J., Carvalho, F. O., Quintans-Junior, L. J., \& Da Silva Almeida, J. R. G. (2016). Development and Evaluation of Stability of a Gel Formulation Containing the Monoterpene Borneol. Scientific World Journal, 2016. https://doi.org/10.1155/2016/7394685

24. Kitawat, S., Saxena, A., \& Gaur, K. (2015). Journal of Chemical and Pharmaceutical Research, 2015, 7 (10): 948-952 Research Article Formulation development and evaluation of aceclofenac sodium gel. 7(10), 948-952.

25. Eurycoma longifolia Jack — The Plant List. (n.d.). Retrieved June 27 , 2021, from http://www.theplantlist.org/tpl1.1/record/kew-2805148

26. Globinmed - Globinmed. (2011). In Centella asiatica.

27. Ahmad, N., Teh, B. P., Halim, S. Z., Zolkifli, N. A., Ramli, N., \& Muhammad, H. (2020). Eurycoma longifolia-infused coffee-an oral toxicity study. Nutrients, 12(10), 1-17. https://doi.org/10.3390/ nu12103125

28. Faisal, G. G., Zakaria, S. M., \& Najmuldeen, G. F. (2015). In vitro antibacterial activity of Eurycoma longifolia Jack (Tongkat Ali) root extract. International Medical Journal Malaysia, 14(1), 77-81. https://doi.org/10.31436/imjm.v14i1.460

29. Alloha, I. B., Aziz, N. A. L. B., Faisal, G. G., Abllah, Z., \& Arzmi, M. H. (2019). Effects of Eurycoma Longifolia jack (Tongkat Ali) alcoholic root extract against oral pathogens. Pharmacognosy Journal, 11(6), 1299-1302. https://doi.org/10.5530/pj.2019.11.201 
30. Faisal, G. G., Zakaria, S. M., Najmuldeen, G. F., \& Al-Ani, I. M. (2016). Antifungal activity of eurycoma longifolia jack (Tongkat ali) root extract. Journal of International Dental and Medical Research, 9(1), 70-74.

31. Tran, T. V. A., Malainer, C., Schwaiger, S., Atanasov, A. G., Heiss, E. H., Dirsch, V. M., \& Stuppner, H. (2014). NF-kB inhibitors from Eurycoma longifolia. Journal of Natural Products, 77(3), 483-488. https://doi.org/10.1021/np400701k

32. victor Y.A Barku. (2019). wound healing : contributions from plant secondary metabolite antioxident. Intech. http://www.intechopen. $\mathrm{com} /$ books/trends-in-telecommunications-technologies/gps-totalelectron-content-tec- prediction-at-ionosphere-layer-over-theequatorial-region \%0AInTec\%0Ahttp://www.asociatiamhc.ro/wpcontent/uploads/2013/11/Guide-to-Hydropower.pdf

33. Zafar, M., Ahmad, M., Sultana, S., Lubna, Anjum, F., Ozdemir, F. A., Tariq, A., Nazir, A., Yaseen, G., Aabidin, S. Z. U., Gul, H., \& Rehman, S. ur. (2019). Light microscopy and scanning electron microscopy: Implications for authentication of misidentified herbal drugs. Microscopy Research and Technique, 82(10), 1779-1786. https://doi.org/10.1002/jemt.23344
34. Dadzie, I., Avorgbedo, S. A., Appiah-Opong, R., \& Cudjoe, O. (2020). Cytotoxic and Antioxidant Effects of Antimalarial Herbal Mixtures. International Journal of Microbiology, 2020, 8-10. https:// doi.org/10.1155/2020/8645691

35. Lai, W. F., \& Rogach, A. L. (2017). Hydrogel-Based Materials for Delivery of Herbal Medicines. ACS Applied Materials and Interfaces, 9(13), 11309-11320. https://doi.org/10.1021/acsami.6b16120

36. Percival, S. L., McCarty, S., Hunt, J. A., \& Woods, E. J. (2014). The effects of $\mathrm{pH}$ on wound healing, biofilms, and antimicrobial efficacy. Wound Repair and Regeneration : Official Publication of the Wound Healing Society [and] the European Tissue Repair Society, 22(2), 174-186. https://doi.org/10.1111/wrr.12125

37. Fleck, A., Cabral, P. F. G., Vieira, F. F. M., Pinheiro, D. A., Pereira, C. R., Santos, W. C., \& Machado, T. B. (2016). Punica granatum L. hydrogel for wound care treatment: From case study to phytomedicine standardization. Molecules, 21(8). https://doi. org/10.3390/molecules21081059 (Fleck et al., 2016).

38. Kajahmohideen $\mathrm{NH}$, Razi SN, Faisal GG, Ashour AE, Kusumawardani A, Makky EA, Ibrahim OE. Cytotoxic Activity of Eurycoma Longifolia Jack Root Extract Against Nasopharyngeal Carcinoma Cell Line. Pharmacognosy Journal. 2021;13(4)

Cite this article: Yaseen MR, Faisal GG, Fuaat AA, Affandi KA, Alallam B, Nasir MHM. Preparation of Euyrycoma Longifolia Jack (E.L) Tongkat Ali (Ta) Root Extract Hydrogel for Wound Application. Pharmacogn J. 2021;13(6): 1456-1463. 